\title{
EL DERECHO PENAL ISLÁMICO Y SU CONCEPCIÓN DE LA PENA
}

\author{
PABLO ORLANDO* \\ Universidad de Buenos Aires
}

\begin{abstract}
RESUMEN: En el presente artículo se tratan las particularidades del Derecho Penal Islámico, partiendo desde las bases y fundamentos de la Sharia Islámica, en general, su concepción de la ley y la pena en la vida del individuo para con la sociedad. Luego se trata la ley penal propiamente dicha, sus fundamentos y sanciones, así también los medios de prueba, intentando demostrar que el fin de la pena es, en sí, el de disuadir a la sociedad de realizar actividades antijurídicas y en la facultad del perdón y la retribución; y no así en la sola aplicación de las penas como un fin.
\end{abstract}

Palabras clave: derecho penal islámico, bases del derecho penal islámico, ley del talión, huddud, tazir, sharia.

ABSTRACT: This article discusses the peculiarities of Islamic Criminal Law, starting from the bases and foundations of the Islamic Sharia, in general, its conception of law and the penalty in the life of the individual to society. Afterwards, it discusses criminal law itself, its foundations and penalties; as well as the evidence, trying to demonstrate that the finality of the punishment is, in itself, to deter the society of committing anti-juridical actions and in the power of forgiveness and retribution; and not in the single application of penalties as a purpose.

Key words: Islamic Criminal Law, bases of islamic criminal law, lex talionis, huddud, tazir, sharia.

En la actualidad que nos toca vivir, hoy más que nunca, resulta difícil y arduo el trabajo de luchar con las nociones preconcebidas, pero a su vez es reconfortante ver que simplemente una correcta exposición del asunto puede cambiar diametralmente ese juicio a priori por una construcción conceptual acabada sobre el tema.

Hoy, son pocos los juristas que reconocen al Derecho Islámico como una ciencia jurídica propiamente dicha, tomándola como referencia al pie dentro de sus obras comparatistas, y además son los menos los que en la faena investigativa lo reconocen a la par del derecho occidental.

Para entender someramente lo que es el Derecho Islámico, hay que explicar lo que es el Islam y sus pilares fundamentales. Islam proviene de la palabra Salam, que es paz, la palabra musulmán significa estar sometido a Dios (Allah), lo que nos lleva al primer pilar que es el de creer en un solo Dios, único con derecho a ser adorado. El segundo pilar es el creer en los profetas y mensajeros, esto es desde Adán, pasando por Noé, Abraham, Moisés, Jesús, entre otros y el profeta muhammad que es sello de los profetas de Dios, el musulmán no hace distinción entre ellos. El tercer pilar es el creer en los ángeles como seres creados de luz por Dios y que solo cumplen órdenes de él, el cuarto es el creer en los libros sagrados, estos son la Torá, los Salmos, el Evangelio y el Corán. Luego el quinto

* Bachiller Universitario en Derecho, Universidad de Buenos Aires U.B.A. Especializado en Sharia Islámica. Egresado del Seminario Islámico Latinoamericano del Centro Islámico de la República Argentina. Funcionario del Centro Cultural Islámico "Custodio de las Dos Sagradas Mezquitas" Rey Fahd en Argentina. 
pilar es el de creer en el destino decretado por Dios ya sea este bueno o malo y por último creer en el día del juicio final donde todos los seres serán resucitados y juzgados por Dios.

Hay más de 1,2 millón de musulmanes en todo el mundo, más del $20 \%$ de la población mundial. Hay 35 países con población de más del 50\% que profesan el Islam y otras 21 naciones que tienen una importante población musulmana. Y además hay 19 países que han incorporado normas islámicas en sus respectivas constituciones.

Lo que es más difícil comprender en occidente de la Ley Islámica (Sharia ${ }^{1}$ ), tal vez a causa de malas experiencias, es la falta de separación entre Religión y Estado. Para el musulmán la religión regula todos los aspectos de su vida y los derechos y obligaciones para con la sociedad y Dios. Vale aclarar que existen diversos grados de aplicación y matices conforme a la tendencia política interna como externa de cada Estado en particular. Y es en este último punto donde comienzan los equívocos al querer realizar un estudio serio sobre el Islam, ya que se toman ejemplos y experiencias, a veces muy poco felices, que el profano en asuntos específicos de la religión, cree que "es el deber ser", y lo que en general es lo que no debería ser sino lo que a algunos les conviene hacer.

El derecho islámico se nutre directamente de la Sharia, por lo que presenta un marcado perfil religioso al que lo estudia desde fuera, por ello es común en un principio creer que hay una confusión de materias en donde la religión y el derecho se identifican. Por ejemplo un acto Sharií que es el realizado en virtud de la decisión de Dios (a través de su revelación) relativa a las acciones de los seres humanos capaces, que expresa una imposición, elección o relación; es el que mejor nos acerca a la concepción musulmana del acto jurídico en su más amplio sentido produciendo efectos jurídicos propiamente dichos. De allí que la legislación islámica no pueda verse separada de la teología y que no pueda hallarse, con evidente facilidad, las similitudes entre la concepción jurídica occidental e islámica, dado que los diferentes institutos que hallan equivalente en nuestro derecho, no revisten en ambos sistemas la misma significación a causa de, además del idioma, el enfoque originario y de base que los caracteriza.

\section{ALGUNAS NOCIONES BÁSICAS SOBRE SHARIA}

Como dijimos anteriormente la Ley Islámica, para el musulmán, regula todos los comportamientos públicos y privados del individuo y de la sociedad en sí, ya profesen el Islam o no. También se puede utilizar para resolver conflictos o situaciones internacionales entre naciones, y todo ello no excluye el conocimiento de otras fuentes de producción.

La Sharia tiene varias fuentes de donde extraer sus principios rectores, y el fundamento de esto se encuentra en el mismo Corán:

[“¡Oh creyentes! Obedeced a Allah, obedeced al Mensajero ${ }^{1}$ y a aquellos de vosotros que tengan autoridad y conocimiento. $\mathrm{Y}$ si discrepáis acerca de un asunto remitidlo al juicio de Allah y del Mensajero, si es que creéis en Allah y en el día

\footnotetext{
${ }^{1}$ Sharia: proviene de la raíz en árabe Sharaá que significa mostrar el camino, prescribir, legislar.
} 
del juicio, porque es lo preferible y el camino correcto"] sura "de las Mujeres" versículo $59^{3}$.

Aquí el mismo Corán nos está informando cuáles son las fuentes del Derecho Islámico y el orden de las mismas.

La primera fuente primaria y fundamental es el Corán (1) “...obedeced a Allah...” es el árbitro final, hay que especificar que, aunque hay traducciones, estas nunca van a ser fieles a su significación en árabe, por lo que en este caso la primera fuente es el Corán en idioma árabe.

La segunda fuente se la conoce como Sunnah ${ }^{4}$ (2) “...obedeced al Mensajero...” que en resumen es todo lo que dijo, hizo, prohibió, y permitió, de la misma forma que ha pasado con todos los profetas desde Adán, pasando por los que conocemos de la Torá, el Evangelio y Jesús, hasta el último profeta y sello de la revelación divina Muhammad ibn Abdullah. Estas tradiciones "Hadiz", al igual que el Corán, también se encuentran en árabe y las dos fuentes de compilación más importantes de la Sunnah, en las cuales no hay discrepancias entre los sabios, son las obras de "Sahih Al Bujari" del imám Al Bujari y el "Sahib Muslim" del imám Muslim.

La tercera fuente es el Ijma, que significa el consenso de los sabios (3) “... y a aquellos de vosotros que tengan autoridad y conocimiento...", y esa autoridad se da solo por estudio y preparación académica, estos sabios son llamados Ulemas que en virtud de un hecho o una consulta, llegan a un consenso sobre el asunto (Ijma) siempre siguiendo como principio rector el Corán y la Sunnah, son los jueces islámicos (qaddi) los que posteriormente aplican la solución abordada por el Ijma al caso concreto. El Ijma asegura a la comunidad musulmana la integración de distintas opiniones, el reconocimiento de nuevos principios que van hallando cabida en el curso de los tiempos. Significa, en fin, la adecuación del nuevo derecho a la sociedad, y al mismo tiempo, de la sociedad a las normas que pacientemente van surgiendo del proceso de elaboración ${ }^{5}$.

Y la cuarta fuente es "Al Quias” la analogía: “...Y si discrepáis acerca de un asunto remitidlo al juicio de Allah y del Mensajero" (4). Consiste en tratar de dar una solución al caso en análisis, mediante la aplicación de soluciones halladas para aquellos que presentan semejanza. De la misma manera, la exención analógica no podrá modificar la ley, y mucho menos modificar las otras fuentes superiores a ella y siempre debe ser utilizada a favor del acusado, nunca en su detrimento.

\footnotetext{
2 Sura: significa en este caso "Capítulo".

3 Sagrado Corán, traducción de su contenido al idioma español 2004, Arabia Saudita: ED. IIPH Riyadh, p. 101. Hay que tener en cuenta que el Corán propiamente dicho, es solo en idioma árabe, las traducciones son de los significados, y es por ello que ante cualquier búsqueda de fundamento jurídico como religioso de algún precepto solo se realiza estudiándolo del árabe mismo.

${ }^{4}$ Sunnah: lingüísticamente significa uso, tradición (del profeta), método habitual.

${ }^{5}$ Brasa, Teresa M.E. Derecho Civil Musulmán. Argentina: Ed. Depalma, 1981, p. 161.
} 


\section{LA LEY Y LA PENA}

Como vimos, el Islam reconoce que la moral y la ética son la base para una buena sociedad. Y la Sharia, como una comunidad de leyes morales, busca el bienestar, salud y seguridad de todos sus miembros por igual, no solo musulmanes, estableciendo normas, penalidades y remedios. A diferencia de las sociedades modernas, donde las leyes son formadas a través de cuerpos legislativos, las reglas básicas y fundamentales de la Sharia son de naturaleza divina.

En consecuencia, las cuatro principales fuentes de cognición para la ley islámica son, como ya dijimos, principalmente el Corán y la Sunnah, luego, el consenso de los sabios y la analogía. También existen otras fuentes auxiliares, pero las principales son las que hemos descrito.

Uno de los principios fundamentales en el Derecho Islámico es el del bará-atudhdhimma (lingüísticamente amparo) que no es otro que el principio de inocencia que nosotros conocemos en nuestros ordenamientos, este principio se deduce lógicamente en lo que se llama "las reglas de jurisprudencia" 6 . Un ejemplo lo encontramos dentro de las tradiciones proféticas "hadices" de la "Sunnah", y con él podremos ver de qué manera se ha transmitido en las obras de los compiladores:

Narro Abú Huraira que el Mensajero de Allah dijo: “Evitad dictaminar las penas prescriptas tanto como podáis" 7 .

Al Baihaqi también transmitió de un Hadiz en el que $\mathrm{Ali}^{8}$ dice: "Dejad de aplicar las penas prescriptas en caso de que exista la más mínima duda”.

Esto significa de que en caso de que exista una duda razonable acerca de alguna evidencia que sea conducente para una eventual condena al acusado, dicha evidencia debe eliminarse de inmediato. Estos "hadices" implican que ningún veredicto sobre algún delito debe ser pronunciado a menos que haya una certeza total sobre las pruebas incluidas en el proceso penal. Los jueces deben abstenerse de procesar a un sujeto a menos que tengan plena certeza de contar con las pruebas suficientes para probar el crimen.

Podríamos decir que el Islam se embarca en la teoría de la prevención de la pena, y parte de ese mecanismo de prevención se basa en la severidad de las penas a fin de evitar que el que cometió el crimen lo vuelva a hacer y como disuasión a la sociedad en su conjunto.

Es por ello que, en virtud del texto del Corán, el Islam aboga por la prevención de la pena, para que esta sea de utilidad, y no únicamente de castigo.

Ello lo encontramos en la definición misma de Huddud, que son los delitos que tienen las penas más fuertes, por así decirlo. La definición técnica de la palabra Huddud "Es el castigo establecido en la ley por un delito que por su gravedad es pernicioso también para

\footnotetext{
${ }^{6}$ Usul alfiqh: significa bases de la jurisprudencia.

7 Transmitido por Ibn Mayah (con isnad Daif). Del libro "Bulug AlMaran, el alcance de lo deseado, de las evidencias de la legislación”. AlHafiz Ibn Hayar Al Asqalani (Compilador), escrito/traducido por Muhammad bin Imail As Sanáni. Arabia Saudita, Ed. Darussalam 2004.

${ }^{8}$ Ali ibn Abi Talib, primo hermano y yerno del Profeta Muhammad.

${ }^{9}$ Ibid., p. 8.
} 
la sociedad en su conjunto"10. La raíz de la palabra proviene de Hadd, que significa prevención, restricción, prohibición, y por lo tanto una ordenanza restrictiva o un estatuto de Dios respecto a las cosas lícitas e ilícitas.

$\mathrm{Y}$ ¡cuál es el objetivo de este tipo de pena?, es la misma definición y raíz de la palabra nos los da:

1. Aplicar la pena al que cometió el delito, el mal está en haber incumplido una norma jurídica.

2. Prevenir a la sociedad del mal que pudiera acarrear el incumplimiento de la norma, demostrando que la violación de la misma lleva como consecuencia una sanción legal. De esta forma se halla justicia en la tierra preservando la vidalhonor y bienes de sus habitantes ${ }^{11}$.

\section{LOS TIPOS DE DELITOS}

Primeramente, para que a una persona comparezca como imputada en un proceso y eventualmente aplicársele una medida de seguridad o una pena, deben concurrir varias características o la ausencia de algunas tal como está explicado en la obra del Dr. Saleh ibn Fausan ibn Abdulah Al Fausan "Mulajas al Fiqui"12:

1. Que la persona sea púber: entiéndase como mayoría de edad, el fundamento de esto lo encontramos en la tradición Profética (hadiz): el Profeta dijo: "tres clases de personas son eximidas de toda responsabilidad religiosa: el Demente hasta que sane, el Dormido hasta que despierte y el niño hasta llegar a la Pubertad"13.

2. Que la persona tenga conocimiento efectivo de lo prohibido, su fundamento está en otra tradición profética: "no se le debe aplicar la pena a quien la ignora salvo que la conozca [la prohibición], relatado por Ali Ibn abi Talib y Omar ibn alJattab"I4. También Ibn Qudama dijo: "esta es la opinión general de todos los sabios.

3. Si están las dos condiciones, no hay impedimento en realizar el debido proceso y eventualmente si corresponde, la aplicación de la pena.

1- Qisas: equivale a la ley del Talión ${ }^{15}$, este es el primero y el más conocido, como ya veremos. Es el imaginario social el que lamentablemente lo interpreta negativamente. Lingüísticamente Qisas significa según todos los comentaristas clásicos, es casi sinónimo de "musawa", o sea, "hacer algo igual a [otra cosa]": en este caso, hacer que el castigo sea igual (o adecuado) al crimen; significado cuya mejor traducción es la de "justa retribución" y no (como erróneamente, ha sido traducido con frecuencia) la de "represalia o

${ }^{10}$ Dr. Saleh ibn Fausan ibn Abdulah AlFausan Mulajas al Fiqu. Reino de Arabia Saudita: Ed Yamia al huqquq mihfuaddtun 2001 , p. 521.

${ }^{11}$ Dr. Saleh ibn Fausan ibn Abdulah AlFausan, op. cit. (n. 10). p. 522.

12 Ibid.

13 Trasmitido en la obra de Abu Daud y otros.

${ }^{14}$ De las obras de Abu Rasaq y Al Baihaqi.

${ }^{15}$ Imam Abi Alhusayn Al Muslim, Sahih Muslim, Tomo IV. Argentina: Ed. Oficina de Cultura y Difusión Islámica, 2004. Véase nota al pie de página 236. 
venganza". Dado que el Corán habla aquí de "casos de homicidio" en general fi 'lqatla, lit., "en el asunto de los matados", y tomando en consideración que esta expresión abarca todos los casos posibles de homicidio, asesinato premeditado, asesinato bajo provocación grave, homicidio sin premeditación, homicidio por accidente (culposo) etc. resulta evidente que tomar una vida por otra vida (como implica el término "represalia o venganza") no se correspondería con las exigencias de la equidad..." 16 . Como veremos seguidamente, tanto en el Corán como en las Tradiciones proféticas (Hadices) a veces se postula castigar con una acción equivalente a la sufrida, o bien se cambia esto por una retribución llamada Diyah "indemnización o precio de sangre", en casos menos graves o cuando infligir el mismo daño es imposible, ridículo o no es conducente. Dice el Corán: “Creyentes! Se os ha prescrito la ley del talión en el asesinato: libre por libre, esclavo por esclavo y hembra por hembra. Pero si a uno su hermano le perdona algo, que este proceda según lo reconocido y que él lo entregue buenamente. Esto es un alivio que Allah os da y una misericordia. Pues, quien vaya más allá de estos límites [tratando de vengarse del homicida], tendrá un castigo doloroso [el día del juicio]". Sura de La Vaca versículo, $178^{17}$.

Aquí vemos que el Talión no es una obligación, pero aunque parezca extraño, ciertamente tiene obligatoriedad en el sentido para que no se cometan excesos y violaciones a la ley con consecuencias graves para la sociedad y el orden publico, esto es en lo que respecta a asesinatos y otros casos. El juicio se sustancia ante un único juez; tras la acusación, se procederá al interrogatorio del acusado y al demandante se le pide que presente las pruebas que fundamentan sus alegaciones, pruebas que acreditan la verosimilitud de los hechos, así también el acusado podrá estudiar las pruebas, impugnarlas y en su caso aportar las suyas propias, lo que puede resultar, en que el juez tome algunas medidas cautelares o de seguridad durante la sustanciación del juicio, o todo lo contrario, también pueden ser morigeradas, a pedido del acusado o de su representante según corresponda.

El derecho procesal islámico ignora el procedimiento por ausencia del demandado, principalmente en delitos de homicidios. Por lo tanto, la no presencia del inculpado implica el desconocimiento de sus argumentos y por lo tanto se violaría su derecho de defensa en juicio, tal como lo conocemos en nuestros ordenamientos.

Si se dice: en la áya (párrafo del Corán) "Se os prescribe aplicar", encontramos una orden obligatoria de aplicar, entonces, ¿cómo la aplicación del Talión no es un acto obligatorio? Se responde: El significado de la áya es: Cuando queráis hacer justicia, aplicadla por medio del Talión para que no haya excesos al cumplirla ${ }^{18}$.

Esto es porque en el periodo preislámico (yahiliah) entre los pueblos árabes, cuando un hombre daba muerte a otro, era protegido por su tribu, y a su vez, la tribu del fallecido tomaba venganza de su sangre, lo que llevaba a ambas tribus a enfrentarse, lo que resultaba en muchas muertes. Entonces, cuando legisló Dios en el Sagrado Corán la aplicación del Qisas, se convencieron todos y dejaron de matarse entre ellos. Es por ello que se interpreta literalmente que encontraron en esta ley la vida.

\footnotetext{
16 http://www.webislam.com/?idt=378

17 Sagrado Corán, op.cit. (n. 3), p. 45.

${ }^{18}$ Imam Al Qurtubi. Compendio del Tafsir (exegesis) del Corán, Tomo 1. España: Ed. Cdad. Musulmana Española de La Mezquita del Temor De Allah, 2005, p. 426
} 
Volvemos al párrafo del Corán que citamos anteriormente: "Pero si a uno su hermano le perdona algo, que este proceda según lo reconocido y que él lo entregue buenamente". Interpretan los Ulemas ${ }^{19}$ : “a uno", se refiere al asesino, y "Le perdona”, o sea, el representante del asesinado y, "Algo", esto es la sangre: le perdona conmutando la pena capital y tomando de él el precio de sangre, o sea la debida indemnización (diía).

Aquí el significado de perdonar es dejar la aplicación del Talión. Si el culpable es perdonado por el representante del fallecido (wali), que pueden ser familiares directos o su representante, este debe dar la indemnización (diía) y entregarla de buena forma (sin atraso), y el representante debe comportarse con él de buena forma también.

El versículo Coránico siguiente es más esclarecedor y establece el objetivo fundamental del Qisas (ley del Talión) en la perspectiva islámica, y lo que la lleva a ponerse en forma diametralmente opuesta al sentido que se le da a la ley del Talión en el imaginario social y académico. Aquí, es Dios en el Corán el que nos informa cuál es el bien jurídico a proteger, y no como medio de castigo, ni menos, de represalia y venganza, apela a la ética, al perdón y misericordia de los involucrados, sin dejar de lado la dura advertencia para toda la sociedad el efecto y sanción que tiene el incumplir en delitos de semejante gravedad: "En el talión tenéis vida ;Oh vosotros que sabéis reconocer la esencia de las cosas! Quizá asi os guardéis" Sura de la Vaca, versículo 179.

Y en otro versículo dice Dios en el Corán apelando a la misericordia humana y al perdón:

"Quien renuncie por generosidad, le servirá de remisión”. Sura La Mesa Servida versículo 45 "En el talión tenéis vida”. Su significado, según lo que relata Sufián, de AsSuddi, de Abu Málik, es: "No os mataréis los unos a los otros"20. Cerrando el tema del Qisas (Talión), podremos ver en el siguiente Hadiz cómo el profeta Muhammad, actuando de juez, hizo aplicar de una forma bien gráfica y clara el versículo Coránico del Qisas y cuál es el fin del mismo:

Alqamah ibn Wail relató que su padre dijo: "Yo estaba sentado junto al profeta [Muhammad] cuando llegó un hombre arrastrando a otro con la ayuda de una correa y dijo: ¡Oh Mensajero de Allah! Este hombre mató a mi hermano. Entonces el Mensajero de Allah preguntó: ¿tú lo has matado? El primer hombre, familiar del asesinado, interrumpió diciendo: ¿si no confiesa debo traer la evidencia contra el? Dijo el acusado: Sí, yo lo maté ${ }^{1}$. Dijo [el profeta Muhammad] ¿Cómo lo mataste? Dijo: él y yo estábamos juntando las hojas de un árbol. Él me insultó, yo me enojé, y entonces le golpee la cabeza con un hacha y lo maté. El profeta le preguntó: ¡tienes algo para pagar el precio de sangre en tu nombre?22. Dijo: No tengo ningún bien excepto esta túnica y esta hacha. Dijo el profeta: ¿piensas que tu gente pagará

\footnotetext{
19 Ulema: Sabio.

${ }^{20} \mathrm{Ibid}$. (n. 18), p. 430.

${ }^{21}$ La confesión del delincuente es considerada como una prueba positiva contra él, si es en forma voluntaria y si está en posesión de sus sentidos, igualmente es el juez en virtud de lo investigado y las pruebas el que decidirá en última instancia.

${ }^{22}$ Las circunstancias muestran que no fue un asesinato intencional y premeditado, si no producto de un ataque de ira. En la Ley Islámica el juez debe considerar al menos cuatro cosas antes de emitir un juicio: la intención y el motivo del crimen, las condiciones y las circunstancias en que fue cometido, además de las pruebas y el resultado del acto criminal.
} 
por ti? ${ }^{23}$. Dijo: soy demasiado insignificante entre mi gente para eso. Entonces el Profeta le arrojó la correa [al hermano de la víctima] y le dijo: llévate tu hombre. El hombre se lo llevo y cuando se iba, el Mensajero de Allah comentó: Si lo mata será como él ${ }^{24}$. Entonces [enterado de lo dicho] volvió y dijo: ¡Oh Mensajero de Allah! Me han comentado que tú has dicho: si lo mata será como él. Siendo que yo me lo lleven siguiendo tus órdenes. Entonces el Mensajero de Allah le pregunto: ¿no quieres que él cargue con tu pecado y el de tu compañero[tu hermano]?25. Dijo: ¡Oh profeta de Allah! Claro que sí. Dijo el profeta: Pues entonces así es como será. Tiró la correa [con la cual estaba detenido] y lo dejo libre"26.

El Qisas no es un medio de castigo, así tampoco de represalia y venganza, Dios en el Corán apela a la compasión y perdón así también a la misericordia de los involucrados dentro del proceso judicial y los beneficios que ello tiene para la religiosidad de cada uno, pero a la vez, sin dejar de lado la dura advertencia para toda la sociedad el efecto y sanción capital que tiene el incumplir en delitos de semejante gravedad.

El Talión es la ley de la balanza, de la equivalencia entre una transgresión y lo necesario para el restablecimiento del equilibrio roto en el seno de la comunidad. Se trata de problemas de energías, de una concepción al mismo tiempo racional y orgánico de la Ley. No se trata nunca de castigar sino de restablecer un equilibrio, de devolver las cosas a su cause.

2-los delitos "Huddud"27: son la segunda categoría, y estos se basan en el Corán y la Sunnah (tradiciones proféticas en general), al igual que sus penas, así como su medio de prueba.

Los primeros son los de fornicación y adulterio: El Corán advierte al musulmán duramente sobre la fornicación "zina” y utiliza el mismo término también para el adulterio:

" $Y$ no os acerquéis a la fornicación pues ello es una indecencia y un mal camino". Sura La Luz, versículo 32.

Aquí esta exhortando a evitar todos los medios que puedan llevar a un hecho punible, considerando a tales actos una inmoralidad innecesaria, ya que se apela a que se conformen matrimonios.

Y es aquí, en un Hadiz Profético, donde se establece la pena a estos actos: relató Ubada Ibn As Samit que el Mensajero de Allah dijo: “...cuando las partes involucradas [en la fornicación] son solteras, deben recibir cien azotes y ser desterradas por el período de un año..."28 en el compendio de Muslim.

\footnotetext{
${ }^{23}$ Su familia o su tribu.

${ }^{24}$ Como el hombre no había cometido el crimen premeditadamente, el profeta Muhammad quería que pagase el precio de sangre (indemnización), pero como esto no era posible temía que el hermano lo matase por venganza.

25 Es decir: por haber matado a tu hermano, cargará con sus faltas y si no se le aplica la pena capital y lo perdonas también cargará con tus pecados, el día del juicio final... y Allah sabe más.

${ }^{26}$ Imam Abi Alhusayn Al Muslim. Sahih Muslim, Tomo IV. Argentina: Ed. Oficina de Cultura y Difusión Islámica, 2004 , p. 244.

${ }^{27}$ Huddud: es el plural de Hadd, que significa prevención, restricción, limitación, prohibición.

28 Es aquí donde los sabios, en su aplicación han optado por la interpretación de que se apliquen los latigazos, es a consideración del juez el asunto del destierro, que generalmente se da con respecto a las reincidencias. Del libro "Bulug AlMaran, el alcance de los deseado, de las evidencias de la legislación”. op. cit. (n. 7), p. 356.
} 
Es seguidamente en el mismo relato donde se establece la pena para el adulterio: “...Pero cuando cometan fornicación luego del matrimonio deben recibir cien azotes y ser luego apedreados [Raym] hasta la muerte" narrado por Muslim²9.

Esta última parte del hadiz demuestra que el adúltero o la adúltera, deben ser azotados y luego apedreados hasta la muerte, pero la mayoría de los Ulemas, opinan que no hay necesidad de azotar, y que solo el "Raym" apedreamiento es suficiente, este procedimiento está basado en otro Hadiz Profético donde se le aplicó solo la pena de apedreamiento a una persona.

Ahora, aquí la pena deviene aparentemente en lo que conocemos nosotros como castigo, y es verdaderamente muy fuerte y terrible. Pero es aquí justamente lo novedoso, que muchos investigadores olvidan, que el Islam ha permitido, hace más de 1.400 años, cuando fue revelado el Corán, que tanto el hombre y la mujer luego del matrimonio, se pueden divorciar ya sea de mutuo acuerdo o por decisión de alguno de los dos por igual: Narró Ibn Omar que el Mensajero de Allah dijo: "Lo más detestable para Allah entre los asuntos permitidos, es el divorcio" 30 .

Y en el Corán: "Si se separan, Dios enriquecerá a cada uno con su abundancia, Dios es inmenso, Sabio" Sura de las mujeres, versículo 130.

Estos castigos son de exhaustivo estudio y examen de las pruebas durante el proceso judicial, aun así, en cualquiera de los dos casos, si la mujer se encuentra embarazada, la mayoría de los juristas opinan que dicho embarazo, por sí solo, no es prueba suficiente ${ }^{31}$.

En la ley Islámica (sharia) el beneficio de la duda, es para el acusado. Es por ello que la determinación de la fornicación requiere tres evidencias estrictas en el siguiente orden: cuatro testigos presenciales (que vieran la penetración) / una confesión (libre y sin presiones) / el embarazo.

Es por ello, especialmente por la carga de la prueba, y las grandes posibilidades que otorga el proceso penal para impugnarlas por parte de la defensa, que se hace de muy difícil aplicación dichas penas. Por lo que son en sí, realmente disuasivas.

Por lo que todo ello nos obliga al estudio del siguiente delito "hadd", el de la injuria o la calumnia según el Corán: "y a los que acusen a las mujeres honradas sin aportar seguidamente cuatro testigos dadles ochenta azotes y nunca más aceptéis su testimonio. Esos son los descarriados”. Sura La Luz, versículo 4.

Aquí es el mismo Corán el que nos da la dura advertencia a las calumnias, estableciendo la pena y el medio de prueba, claro está, que el régimen probatorio es el mismo, los testigos deberán haber visto directamente el acto sexual y la penetración, además de acreditar de qué manera lograron ser testigos. Lo que conlleva una difícil tarea probatoria, que en caso de no ser suficiente, es el acusado el que podrá pasar a ser denunciante, y es en este caso que la prueba defectuosa por parte de o los calumniadores será utilizada en contra de ellos mismos.

Es aquí, en consecuencia, que la pena es realmente advertidora para con el potencial denunciante, que deberá pensarlo muy bien y estudiar profundamente la calidad de la

\footnotetext{
29 Ibid.

30 Ibid

${ }^{31}$ Imam Abi Alhusayn Al Muslim, op. cit. (n. 26), p. 253 en Nota al pie 9.
} 
prueba antes de lanzar semejante acusación sobre el honor de una persona, ya sea hombre o mujer.

Y es así, que además de imponer una carga probatoria muy exigente, para disuadir al potencial calumniador, que el Corán otorga otra posibilidad para el que haya denunciado: "a excepción de los que se retracten después de haberlo hecho y rectifiquen, pues en verdad Allah es perdonador y compasivo". Sura La Luz, versículo 5.

Esto significa que dentro del proceso legal, el calumniador puede retractarse de lo denunciado y además rectificarlo, lo que significa que debe dejar intacto el honor de la persona calumniada y además rectificar su interpretación del hecho a fin de que quede restablecida en forma pública la dignidad y buen nombre de la persona involucrada.

Siguiendo con los delitos, el siguiente es el de beber embriagantes, aquí es Dios en el Corán, el que nos advierte sobre el peligro del consumo de ellos: “¡Oh, creyentes! Los embriagantes, los juegos de apuesta, los altares [sobre los cuales eran degollados los animales como ofrenda para los ídolos] y consultar la suerte valiéndose de flechas son una obra inmunda de Satanás. Absteneos de ello y así tendréis éxito”... Sura de La Mesa Servida, versículo 90.

Y sigue: "Satanás solo pretende sembrar entre vosotros la enemistad y el odio valiéndose de los embriagantes y los juegos de apuesta, y[así de esta forma] apartaros del recuerdo de Allah y la oración. ¿Acaso no vais a absteneros?”. Sura de la Mesa Servida, versículo 91.

En idioma árabe el significado de literal de Jamr es esconder, cubrir u ocultar. Cuando el resultado de lo que produce la sustancia consumida es de embriaguez, intoxicación, y altera la mente es lo denominado por la palabra Jamr. En la terminología de la legislación islámica, todo lo que produce intoxicación o embriaguez es prohibido "Haram", claro que hay situaciones en los cuales se permite estas sustancias, cuando su intención y objetivo tiene otro contexto, a ser por ejemplo en casos de emergencias, u otros parecidos.

En un Hadiz profético establece con qué se puede hacer embriagantes y cuál es el efecto que produce a fin de saber cuál es el elemento tipificante de la norma: Dijo Omar ibn AlJattab: "la prohibición del embriagante descendió, y este es hecho de cinco cosas: la uva, el dátil, la miel, el trigo y la cebada. Jamr es todo aquello que embriaga la mente" 32 .

El propósito del hadiz mencionado es primero evidenciar que no solo con uva se hacen embriagantes y además que todo Jamr es aquello que embriaga la mente, por lo que termina con una regla general para que el juez pueda discernir qué es embriagante y qué no.

Ahora veremos la pena prescripta para el beber embriagantes en el siguiente hadiz profético: Narró Anas Ibn Malik que un hombre había bebido vino, fue traído ante el profeta y dio la orden de que fuera azotado con aproximadamente cuarenta azotes, utilizando dos ramas de palmera. Dijo [Anas]: Asimismo hizo Abu Bakr ${ }^{33}$, pero cuando Omar [ibn Aljattab] ${ }^{34}$ fue califa consultó a las personas, y Abdurrahman ibn Auf le dijo: el castigo mínimo son 80 azotes. Por lo que Omar ordenó que así fuera”35.

\footnotetext{
32 Transmitido por las Obras del Imam Albujari Y el Imam Muslim.

$331^{\text {er }}$ Califa del Islam luego de la muerte del profeta Muhammad,

34 20 Califa del Islam luego de la muerte de Abu Bakr, llamado Príncipe de los Creyentes.

35 Transmitido en las obras de los imanes AlBujari y Muslim.
} 
Aquí, sabemos que durante los días del profeta y Abu Bakr la pena para quien consumiera embriagantes eran cuarenta azotes. Sin embargo Omar ibn AlJattab aumento el castigo a ochenta durante su califato. Pero debido a que el castigo de ochenta azotes no existía durante los días del profeta la mayoría de los Ulemas sostienen que el castigo son cuarenta azotes.

El objetivo aquí de la pena por tomar embriagantes es, primero, procurar la salud del individuo pero también el de la sociedad, dado que también son severamente penadas la fabricación y comercialización de embriagantes, salvo, los que se realizan bajo supervisión estatal con fines médicos u otros específicos.

Luego tenemos el delito de robo, el cual es también severamente penado, en el Corán nos señala claramente: "al ladrón y a la ladrona cortadles la mano en pago por lo que hicieron. Escarmiento de Allah; Allah es poderoso, sabio". Sura La mesa Servida, versículo 38 y esto se complementa con tradiciones proféticas: Narró Aisha ${ }^{36}$ que el mensajero de Allah dijo: "no se corta la mano del ladrón salvo que el robo alcance un cuarto de Dinar o más"37.

Sobre este punto existen diferentes opiniones entre los ulemas respecto del valor de lo robado que hace al sujeto acreedor de la pena establecida. Y un estudio basado en varias tradiciones proféticas y el estudio de los sabios demuestra que cualquier acto de robo inferior al valor de un Dinar no es punible con el corte de la mano y un cuarto de Dinar equivale al valor de un gramo y medio de oro.

Luego se hace una distinción entre los siguientes delitos: Relató Yaber que el profeta dijo: "el corte de mano no es aplicable a una persona desleal, un malversador o un saqueador" 38 .

La distinción significa que el saqueo es privar a una persona de sus bienes con violencia, la malversación es utilizar en su favor los bienes de otra persona durante su ausencia y/o sin su conocimiento, y el desleal es la persona que ha sido confiada para proteger ciertos bienes que pertenecen a otra persona y esta persona en secreto y sin aviso huye con ellos, las penas de estos actos difieren según la consideración del juez y los antecedentes jurisprudenciales específicos.

Para probar el delito de robo deben ser considerados dos factores: a) el artículo robado debe ser recuperado y usado como prueba, lo que significa que debe ser ingresado al proceso judicial respetando las garantías de defensa del acusado y b) la propia confesión o la presentación de testigos. Pero sobre esto último hay diferentes opiniones prevaleciendo que si el sospechoso no confiesa ni tampoco se recupera el artículo en su propiedad para que pueda ser utilizado como prueba, el solo testimonio de testigos es considerada una prueba muy débil.

Este es uno de los castigos más disuasivos en el Islam, la tasa de criminalidad de este tipo es muy bajo en los países que aplican este tipo de penas. Aun así como vimos en los demás delitos comentados la calidad de la prueba presentada debe ser determinante, lo que conlleva también a una difícil aplicación por parte de los tribunales en medio oriente.

\footnotetext{
${ }^{36}$ Esposa del profeta, la primer jueza del Islam.

37 Del libro "Bulug AlMaran, el alcance de los deseado, de las evidencias de la legislación”. op. cit. (n. 7) p. 363.

38 Transmitido por la obra de Ahmad y los cuatro libros de Sunnah. Del libro "Bulug AlMaran, el alcance de los deseado, de las evidencias de la legislación”. op. cit. (n. 7), p. 364.
} 
Por último, tenemos los delitos que entran en la categoría de los llamados Tazir que significa literalmente reprimenda, dentro del cual se permite al juez establecer cual es el castigo a los demás delitos que no han tenido una pena específica y son menos graves que los que están estipulados en el Corán o específicamente en las tradiciones proféticas. En varios Estados de medio oriente estos casos están establecidos en leyes y códigos que sus legislaturas o gobernantes han dictado, tal como los conocemos en occidente. Algunos de los delitos son: el soborno, la venta de productos contaminados o defectuosos, la usura, la venta de imágenes obscenas, y algunas de las penas más comunes son: multas, incautación de bienes, el establecimiento de medidas cautelares diversas, como por ejemplo la prisión domiciliaria, y hasta en algunos casos los castigos corporales.

Tenemos que tener en cuenta que el tipo de leyes y su aplicación varía según los países y sus "particulares" regímenes de gobierno, así por ejemplo el consumo de embriagantes se pena de forma distinta en Egipto, que en Irán o Arabia Saudita.

En fin, nos toca hablar un poco sobre el sistema carcelario islámico, así como afirmamos que el propósito del Qisas "Talión” es asegurar la vida de la sociedad, y prevenir la reincidencia, en el Islam, las cárceles (deber ser) tienen que ser un lugar de resociabilización del reo, y también dependiendo del caso, una protección para él y para la sociedad. Es por ello que comúnmente se dice que se antepone el derecho de la sociedad sobre el derecho de un solo individuo. Pero aun así, el sistema no se olvida del reo, se lo reeduca, no solo en aspectos religiosos, sino también se lo intenta reinsertar en la sociedad a través de oficios y contención psicológica y afectiva, por ejemplo, en Arabia Saudita, una de las principales labores de los egresados de las universidades de Sharia Islámica, y de las carreras religiosas es el de realizar visitas y prácticas en las cárceles de su país, por el cual se benefician ellos con la experiencia ganada y además beneficia a los habitantes de las cárceles al visitarlos y realizar talleres sobre diversos asuntos y actividades útiles.

\section{CONCLUSIÓN}

Lo más importante para la comunidad islámica es someterse al legislador divino y el marco social que le impone. La Sharia Islámica supone que con su conducta el musulmán se compromete a sí mismo y que un día comparecerá ante Dios a dar cuenta de cada una de sus obras.

Y es allí donde está el punto más importante del asunto, en la certeza de ese juicio divino que con cada acto que realiza el individuo lo acerca o lo aleja más del infierno el día del juicio.

El Islam da preferencia a la voluntad de Dios en este mundo, por encima de las personas y es por ello que la religión rehúsa quitar a Dios del control de los asuntos mundanos del musulmán y establece la obediencia total a sus normas. Ningún ser humano, sin excepción, tiene derecho a permitir que sus propios deseos y acciones estén en oposición a esas normas provenientes de Dios.

Como ya vimos, el Islam establece castigos, que van desde el Talión "Qisas", los castigos personales y corte de manos. $\mathrm{Y}$ es esto, las penas y castigos, lo que se estudia 
primeramente al abordar este asunto desde la perspectiva islámica pero en ese estudio realizado desde la periferia, se olvida las particularidades que ofrece el Islam al perdón, la compasión y equidad. Y es por ello, donde se diferencia el Islam, ya que el fin de la pena es el de la disuasión a realizar las conductas antijurídicas, primeramente por que el Islam es una religión que fue revelada por Dios para facilitar los asuntos al hombre, estableciendo salidas para no tener que cometer delitos o conductas antijurídicas, como por ejemplo hace 1.400 años que Allah legisló el divorcio como facultad para ejercer por la mujer o el hombre por igual, a fin de que el individuo evite el adulterio y la pena impuesta para el mismo. Y más aún, estableciendo una alta calidad de prueba a fin de poder aplicar la legislación, y además por último en muchos pasajes del Corán realza la importancia y bendiciones de Dios para con la persona que se arrepiente, se retracta y rectifica; y por otro lado al que perdona, en el Talión "Qisas" es donde tenemos un ejemplo de lo meritorio que es para los familiares del fallecido el perdón y la aceptación de una indemnización y así encontrar vida en la retribución.

\section{REFERENCIAS BIBLIOGRÁFICAS}

"Sagrado Corán", traducción de su contenido al idioma español 2004, ED. IIPH Riyadh Arabia Saudita.

Brasa Teresa M.E. “Derecho Civil Musulmán” ed. Depalma 1981, Pág. 161. Argentina.

“Bulug AlMaram, el alcance de los deseado, de las evidencias de la legislación”. Ed. Darussalam 2004, Arabia Saudita. Compilador AlHafiz Ibn Hayar Al Asqalani, escrito/traducido por Muhammad bin Imail As Sanan.

Dr. Saleh ibn Fausan ibn Abdulah AlFausan "Mulajas al Fiqui”, ed Yamia al huqquq mihfuaddtun 2001, pág 521. Reino de Arabia Saudita.

Imam Abi Alhusayn Al Muslim, "Sahih Muslim", tomo IV, nota al pie de página 236. Ed. Oficina de Cultura y Difusión Islámica, Argentina, 2004.

Imam Al Qurtubi “Compendio del Tafsir (exégesis) del Corán”, tomo 1, página 426, ed. Cdad. Musulmana Española de La Mezquita del Temor De Allah, España, 2005. 
